\title{
AS POLITICAS DE LÍNGUAS SOBRE O GUARANI NO PARAGUAI E O BILINGUISMO IMAGINÁRIO
}

Joyce Palha Colaça

(UFS)

\section{RESUMO}

O artigo que aqui se apresenta é um recorte de nossa tese de doutorado, em que analisamos discursivamente a construção do lugar que ocupa o guarani no Paraguai, como língua oficial na atualidade. Para tanto, filiamo-nos às pesquisas desenvolvidas no âmbito da História das Ideias Linguísticas (AUROUX, 1998, 2009 [1992], 2010 [1994]; ORLANDI, 1983, 1988, 2008 [1990]), em seu entrelaçamento com a Análise do Discurso de linha francesa (PÊCHEUX, 1988 [1975], 1990 [1969]; 2010 [1994]), para construir nossa reflexão e avançar nos estudos referentes ao tema. Objetivando compreender os sentidos produzidos acerca do imaginário de bilinguismo, analisamos as ações da Secretaria de Políticas Linguísticas, a partir da descrição de três projetos, dentre os quais selecionamos o intitulado Rohayhu Che Ñe'ẽ: una semana en lengua guarani ${ }^{1}$. Observamos o funcionamento dos discursos sobre o guarani no espaço de enunciação (GUIMARÃES, 2005) paraguaio e, também, no latino-americano, por sua incorporação como língua oficial de trabalho do Mercosul. Pela análise empreendida, foi possível verificar como a memória (PÊCHEUX, 2007) sobre as línguas se inscreve na produção de políticas de línguas sobre o bilinguismo, pela promoção de um bilinguismo imaginário. No jogo das relações de forças travadas no embate entre as línguas, nas textualidades analisadas, materializam-se os efeitos de sentidos produzidos ideológica e historicamente, em um processo que segue promovendo a língua espanhola e silenciando a língua guarani no Paraguai.

PALAVRAS-CHAVE: História das Ideias Linguísticas; políticas de línguas; língua guarani; bilinguismo imaginário. 


\section{Uma breve introdução em História das ldeias linguísticas}

A atual Constituição da República do Paraguai, promulgada em 1992, oficializou a língua guarani, juntamente com o espanhol, produzindo novos dizeres sobre as línguas desse país e sobre o próprio país, significando-o como bilíngue.

Podemos afirmar que, no panorama histórico e linguístico da América Latina, o reconhecimento oficial do guarani inaugura a possibilidade de uma nova rede de sentidos, que inscreve, discursivamente, a língua guarani no lugar da instituição, da lei e de um jogo político novo que implica relações de inclusão e de exclusão - e até de interdição - das demais línguas do país, com as línguas indígenas, com a língua de fronteira - na relação específica que aí se trava com o português do Brasil - ou, ainda, com as línguas de imigração. Na realidade pluricultural paraguaia, o guarani é a única língua de origem indígena oficializada em proporção nacional, no continente americano, falada também pela população não indígena, como aponta Niro (2010). Baseados, então, nas determinações da Carta Magna em vigência, perguntamo-nos: 1. O que significa para o guarani ser língua oficial da república paraguaia? 2. Quais são, então, as ações no âmbito político, econômico e social que possibilitam que a língua guarani funcione no real como língua oficial? 3. Como o Estado atua pela promoção da língua guarani em sua disputa pelo espaço de enunciação paraguaio com a língua espanhola? 4. Como são significados o guarani e o espanhol nos projetos da Secretaria de Políticas Linguísticas do Paraguai? 5. O que significa para a língua guarani estar em situação de bilinguismo com a língua espanhola?

Pretendemos fazer um percurso que objetiva compreender os modos de produção dos sentidos sobre as línguas guarani e espanhola no Paraguai, trazendo para este estudo algumas questões formuladas no campo da História das Ideias Linguísticas (AUROUX 2009 [1992]; ORLANDI, 1988, 2008 [1990]), na aliança que vem fazendo com a Análise do Discurso de linha materialista no Brasil.

Escrever uma História das Ideias Linguísticas sobre uma língua de origem indígena significa pôr em discussão as disputas históricas, territoriais e linguísticas, nas línguas e sobre as línguas, colocando em relação os sentidos que aparecem como evidentes nas formulações das políticas de línguas no Paraguai, e, principalmente, aquelas que circulam 
no cenário linguístico nacional como políticas pró-bilinguismo.

No Paraguai, o guarani ocupa um lugar (CELADA, 2002) de língua oficial/nacional/materna, entretanto é preciso desnaturalizar esses sentidos, no caso, com base no suporte teórico-metodológico ao qual nos filiamos. Analisar as línguas dos países que foram colonizados é buscar compreender, de certa forma, a constituição dos novos Estados Nacionais, criados a partir da projeção da imagem de unidade, a qual incide também na formação de imaginários de língua nacional.

Objetivamos pensar nosso arquivo discursivamente como textos produzidos em determinadas condições de produção, que guardam sua relação com a memória (PÊCHEUX, 2007) e com o interdiscurso (PÊCHEUX, 1988 [1975]), e que, desse modo, significam, produzindo efeitos de sentidos. Nessa relação com a memória, o que se disse sobre as línguas em determinadas condições históricas de produção faz ressoar sentidos para a língua guarani e para a língua espanhola na atualidade.

Também pelo funcionamento do "discurso sobre" (ORLANDI, 2008 [1990]) a memória das línguas no Paraguai, foi construída uma imagem de nação bilíngue, que teve seu reconhecimento oficial na Constituição Nacional de 1992, vigente na atualidade, na qual se institui, por meio de uma política de línguas, o que chamamos de bilinguismo oficial. $\mathrm{Ou}$ seja, há um efeito de reconhecimento oficial de uma situação de bilinguismo nos documentos que dizem sobre as línguas do Paraguai, e que, contudo, não promovem uma sociedade bilíngue. Desse modo, ainda que circule um efeito de que a República do Paraguai considere oficialmente o guarani materializado nas políticas linguísticas, fora de tais políticas, a língua guarani ainda ocupa um lugar de língua familiar (vinculada ao âmbito familiar), língua para ser falada entre os pares (MELIÀ, 2013), não sendo reconhecido o seu lugar de língua oficial nas instituições públicas do país (ZARRATEA, 2011).

Por ser uma relação estabelecida historicamente, cujos sentidos são construídos ideologicamente, consideramos a não evidência do lugar que cada língua ocupa no imaginário dos falantes de determinado espaço. Tomamos aqui espaço, lembrando as colocações de Guimarães (2005) e Branco (2013), em dois aspectos distintos e que definem, discursivamente, a relação entre a língua, o espaço e seus falantes. Para Guimarães,

os espaços de enunciação são espaços de funcionamento de línguas, que se dividem, redividem, se misturam, desfazem, transformam por uma disputa incessante. São espaços 'habitados' por falantes, ou seja, 
por sujeitos divididos por seus direitos ao dizer e aos modos de dizer.

(GUIMARÃES, 2005, p. 18.)

São, segundo o autor, espaços em que o político se inscreve numa disputa pelos sentidos. Complementarmente, podemos trazer o desenvolvimento sobre espaço no estudo de Branco (2013), que fala da língua portuguesa "em espaço". Branco (2013) buscou um modo de falar sobre a língua portuguesa do/no Brasil, de/em Cabo Verde etc., na tentativa de sair da evidência da unidade da língua, tratando-a como língua em espaço brasileiro, em espaço cabo-verdiano etc., apontando também, desse modo, os diferentes funcionamentos discursivos da língua portuguesa, por se conformarem de modo distinto nos diferentes lugares que ocupam.

Apoiados nessas formulações sobre "espaço", podemos nos voltar para a relação já posta por esses autores entre língua e Estado, com o objetivo de não considerar este último somente como espaço geograficamente determinado, mas como lugar de disputa de sentidos de línguas e de sujeitos. Assim, consideramos que as línguas guarani e espanhola disputam politicamente o espaço de enunciação paraguaio, num embate entre si, como línguas reconhecidamente oficiais, e num embate com as outras línguas que não figuram como oficiais no cenário linguístico nacional.

Partindo dessas considerações, é nosso objetivo compreender o que se diz sobre as línguas indígenas e o espanhol em sua relação com o sujeito em um sistema republicano determinado, em um espaço de disputas no político, significado como bilíngue pelas leis que regulamentam o ser cidadão, bem como compreender os sentidos nas práticas sociais que, para além do que está escrito no texto da lei, também determinam efeitos de sentidos para um ser sujeito nacional ou para um ser cidadão nesse dado Estado.

Nesse cenário, o guarani passa a ser significado como língua nacional, ao lado do espanhol, e o funcionamento do discurso sobre uma língua nacional, além de implicar o apagamento das demais línguas existentes, implica o apagamento da fluidez (referida, com frequência, como variedade ou variedades) dessa língua, e isso materializa-se pelo processo de gramatização, ao estabelecer limites para as línguas. De acordo com Auroux (2009 [1992]), o processo de gramatização provoca a escolha de uma variedade da língua em detrimento de outras tantas, e essa escolha sobre a variedade que será gramatizada apoia-se sobre "uma discussão do que seja bom uso", num trabalho de inclusão e de exclusão de formas que as classifica e as coloca em status diferentes diante dos falantes, produzindo, 
também, uma "classificação" dos próprios falantes: os que falam bem, os que não, ou os que não sabem a sua língua.

Em um estudo que tem o objetivo de articular os saberes da linguística e da economia, Mariani (2008) propõe uma questão norteadora - "Quanto vale uma língua?" - a partir da qual analisa um enunciado que tem circulado: "língua como variável econômica". No artigo resultante da pesquisa, a autora analisa as diferentes discussões sobre a língua e seu valor econômico, considerando a dominação dos países ditos desenvolvidos sobre os países de terceiro mundo. A autora trata ainda das políticas linguísticas para a manutenção de um país bilíngue ou multilíngue. Em referência à discussão proposta pela autora, nos dias de hoje, a instituição de uma língua oficial também é uma questão econômica. $\mathrm{O}$ valor da língua, dessa perspectiva, tem a ver com o interesse de investimento do Estado em uma ou outra língua, ou duas, no caso de bilinguismo. Assim, como afirma Mariani, é possível perguntar-se quanto custa ser falante de determinada língua em um país colonizado ou quanto custa sê-lo em um país bilíngue. Como pergunta Mariani, "qual o custo de um monolinguismo em um país de terceiro mundo?" (2008, p. 11). A questão da língua é uma questão do Estado, como já assinalavam Gadet e Pêcheux (2010 [1981]), e, retomando o que diz Mariani (2008), podemos afirmar que é também uma questão econômica do Estado.

A partir das reflexões postas e da ideologia da língua única, sustentada na atualidade pelo discurso da globalização, promovendo uma língua de comunicação universal, quanto custa manter um país monolíngue em que não é o inglês a língua oficial? Ou, de outro modo, como promover um nacionalismo plurilíngue se isso demandaria mais investimento? Essas questões propostas pela autora levam-nos ao encontro de nosso objeto, em que podemos pensar o custo da promoção do bilinguismo no Paraguai. De nossa perspectiva, duas questões colocam-se: 1. quanto custou - e ainda custa - promover o espanhol como língua oficial no Paraguai? e 2. quanto custa promover o guarani como língua oficial no Paraguai? Pelos discursos sobre a manutenção da língua espanhola e pela promoção do bilinguismo no Paraguai, mesmo que o guarani seja língua materna da maioria da população, bem como língua nacional, pela ideologia da comunicação mundial, parece não ter lugar a discussão para um Paraguai monolíngue falante de guarani.

O processo de colonização e, em consequência, de uma imposição da cultura europeia faz com que a aceitação desses costumes e de 
uma língua para a entrada no mercado seja significada como evidente, sem que se discutam as questões referentes à própria dominação. Não se discutem, de igual modo, as políticas de línguas em prol dessa unidade e dessa adaptação a um mundo globalizado. E assim, pelo discurso do conhecimento científico, sobretudo o formalista-logicista (PÊCHEUX, 1988 [1975]), vão sendo escondidas as lutas político-ideológico-social-histórico-econômicas que se apresentam nas línguas e nas políticas de línguas. Uma língua, por vezes falada por determinada comunidade linguística, nunca chegará a ocupar o status de língua oficial pela sua impossibilidade política e econômica, o que significa dizer que não é uma questão natural a que irá determinar a dominação; são, por sua vez, questões históricas, políticas e econômicas que contribuirão para tal. É pelo discurso sobre a necessidade de uma língua para a comunicação mundial, pela globalização que se instituem as línguas que podem figurar nesse ambiente internacional. Pelo funcionamento ideológico no discurso sobre as línguas, parece impossível não falar o inglês atualmente, assim como não é possível a promoção do guarani, do quéchua ou qualquer outra língua minoritária, por exemplo.

Avançando em torno dessas considerações, podemos trazer ainda outra discussão que se refere às políticas do plurilinguismo. A respeito disso, interessam-nos as análises de Mariani (2008b) e de Branco (2013), em que as autoras discutem as políticas de línguas sobre a língua portuguesa em África. Branco pergunta-se até que ponto as políticas pelo plurilinguismo realmente o promovem, visto que o que há é um apagamento das outras línguas, pelo discurso da $\mathrm{CPLP}^{2}$, por sua indeterminação, e a produção de um sentido para a língua portuguesa como aquela que deve agregar os países membros, uma língua portuguesa que possibilitaria, inclusive, o desenvolvimento econômico dos países africanos. As análises de Branco (2013) seguem os questionamentos de Mariani (2008b), quando esta se pergunta sobre valor da língua, como apontamos anteriormente, e questiona sobre quanto custa ser plurilíngue ou monolíngue numa língua reconhecidamente minoritária. Branco, então, dirá que esse plurilinguismo determina e direciona para uma divisão nas línguas que continua apontando para a necessidade de uma língua para a comunicação (em seu estudo é analisada a língua portuguesa nesse lugar), regulamentada e legitimada, cujos sentidos continuam promovendo uma hierarquização apagada pelo dizer sobre um gesto de reconhecimento da diversidade. De nossa perspectiva, podemos dizer que, no estado paraguaio, o guarani, 
também reconhecido oficialmente, aparece igualmente como símbolo do respeito à diversidade linguística, o que, de fato, acaba não ocorrendo, já que é o espanhol o requerido nas situações de uso formal da língua, como observam Zarratea (2011) e Melià (2013), dentre outros. Por conseguinte, o próprio reconhecimento da diversidade faz ressoar (SERRANI, 1991) sentidos que circulam e que se fazem produtivos pela manutenção e reprodução da ordem vigente.

Retomando Orlandi, podemos afirmar que, "os sentidos funcionam pelo fato mesmo de circularem. Um discurso que fala do índio é como o discurso sobre o pobre: é produtivo nas relações de poder" (2008 [1990], p. 144). Ao circularem os sentidos sobre o pobre, sobre o índio, sobre os moçambicanos, cabo-verdianos ou angolanos, reproduzem-se os mesmos modos de "dizer sobre" (ORLANDI, 2008 [1990]; MARIANI, 1998), em que se silenciam os seus próprios dizeres, configurando-se assim um modo bastante produtivo de manutenção das relações de poder, que promovem a permanência de tudo como já estava, uma organização daquilo que já se reproduzia no discurso da colonização. É desse modo que se dá, de nossa perspectiva, o funcionamento do discurso sobre o guarani na memória discursiva.

O "dizer sobre" é um modo de silenciar o "dizer do", o dizer do africano, o dizer do índio, ou seja, como já foi dito, é o funcionamento do "discurso sobre" (ORLANDI, 2008 [1990]) operando efeitos de sentido sobre as línguas e na memória discursiva destas. "Fazer dizer" (HAROCHE, 1992) também em português ou em espanhol é fazer não dizer em cabo-verdiano ou em guarani, por exemplo.

Sob essa perspectiva, é necessário compreender discursivamente os processos de produção dos sentidos em sua materialidade linguística e histórica, em que a língua significa em sua relação com a história. Esses sentidos que ressoam na memória comparecem no momento de formulação das políticas que incidem sobre as línguas.

\section{Uma História das ldeias Linguísticas do Guarani}

Considerar a história das ideias sobre as línguas no Paraguai é contar a história das ideias sobre as línguas indígenas naquele país e em outros países da América Latina, sempre em confronto com as línguas dos respectivos colonizadores. Os processos de colonização linguística repetiram-se extensivamente no continente americano, principalmente, nos primeiros contatos entre europeus e indígenas ainda nas colônias, 
quando o encontro entre pelo menos dois imaginários (MARIANI, 2004) era inevitável, instaurando sentidos sobre as línguas até a atualidade. Por esse inevitável encontro que se deu com a chegada dos europeus em território americano e sua violenta entrada nas sociedades americanas, sentidos sobre as línguas foram-se delineando, inscritos numa rede de dizeres sobre os falantes de cada língua que habitavam esse espaço de embate. Assim, os dizeres sobre os índios passam a se estender e fazem circular sentidos sobre suas línguas. Os indígenas passam a ser significados como não civilizados, bárbaros e selvagens, sentidos que atribuiriam também às suas línguas, incompreensíveis ${ }^{3}$.

Quando se trata de pensar nas políticas sobre as línguas na atualidade pela perspectiva discursiva, é fundamental questionar-se sobre os sentidos que ali comparecem, por serem estes construídos historicamente. É preciso dizer que os sentidos não têm origem verificável, entretanto a historicidade dos processos de produção significantes nos permite dar a conhecer certos direcionamentos que foram-se inscrevendo e circulando por meio da história da sociedade paraguaia e de suas línguas.

Os dizeres sobre as línguas do Paraguai fazem circular sentidos sobre estas e sobre todas as políticas de línguas que promovem o guarani, e algumas questões que se delineiam giram em torno do purismo da língua: 1. Que guarani se deve promover? 2. É possível um guarani puro? 3. Se se defende um guarani puro, como criar palavras na língua guarani que atendam às diferentes demandas oficiais da língua ${ }^{4}$ ?

Pela leitura dos estudos em História das Ideias Linguísticas, podemos apontar, inicialmente, que não existe uma língua pura e, principalmente, pela historicidade do processo de gramatização das línguas indígenas, já afirmamos que não é possível um guarani que desconsidere a memória da língua espanhola. A língua da colonização funciona como marca na estrutura da própria língua guarani. Se não existe possibilidade de língua pura, aceitar o guarani paraguaio seria, então, o primeiro passo para a possibilidade de um futuro da língua indígena no Paraguai. Entretanto, considerar a língua espanhola nesse processo é também considerar, nesse confronto, o que exatamente impede a língua guarani de ocupar todos os espaços de dizer nessa sociedade.

Promover a língua guarani na sociedade paraguaia atual é promover uma língua fora da sua história. Entretanto, como fazer diferente se, num mundo supostamente globalizado e industrializado, os conhecimentos hão de ser compartilhados de modo a garantir uma igualdade para além 
das fronteiras do nacional? A história não tem retorno, não é possível mudar a sociedade de modo que ela comporte um guarani puro, que possa dizer do seu mundo na atualidade. Entretanto, é preciso considerar essas questões como fundamentais quando se trata da formulação de políticas sobre as línguas no Paraguai. Não se trata de uma marca da colonização na sociedade, trata-se de uma mudança na concepção do que é sociedade desde o confronto passado já há mais de cinco séculos. Esses sentidos que ressoam (SERRANI, 1991) na memória discursiva comparecem no momento de formulação das políticas que incidem sobre as línguas e sobre as leis que regulam a educação no Paraguai.

\section{A Secretaria de Políticas Linguísticas e as políti- cas de línguas sobre o bilinguismo}

No cenário político, econômico e linguístico, como apresentamos no decorrer deste texto, a língua guarani e a língua espanhola ocupam diferentes lugares no imaginário do espaço de enunciação paraguaio. Com a promulgação da Lei de Linguas, em 2010, abriram-se novas discussões sobre a expansão dos usos da língua guarani nesse país. Dentre as diretrizes dessa lei, a criação da Secretaria de Políticas Linguísticas do Paraguai é um marco na promoção da língua de origem indígena. Nessa Secretaria, há um setor destinado à planificação linguística, a Direção Geral de Planificação Linguística, que tem como principal objetivo elaborar e promover as proposições da Lei de Línguas que, como previsto no Art. 34, em termos gerais, destinam-se a expandir o uso da língua guarani aos setores da sociedade em que o espanhol é predominante, como as instituições públicas e os meios de comunicação, por exemplo. Isso significa que se ocupam de garantir que a língua guarani deixará de fazer parte somente do âmbito privado, familiar e informal.

Dentre as ações da Secretaria de Políticas Linguísticas desde sua fundação, podemos observar a assinatura de convênios entre instituições, a realização de traduções do espanhol ao guarani de diversos tipos de materiais públicos, a implementação de logotipos bilíngues e a produção de três projetos. Justamente, para compor nossa análise, selecionamos um dos projetos, o projeto "Rohayhu Che Ñe' é : una semana en lengua guarani", dentre os criados e promovidos por essa Secretaria, na tentativa de compreender o funcionamento do discurso sobre o bilinguismo na textualidade produzida no interior de um órgão que tem como principal função, segundo os objetivos apresentados na própria 
Lei de Linguas, promover as duas línguas oficiais do país em situação de bilinguismo.

A constituição dos estados nacionais inscreve-se em uma memória que projeta a unidade linguística imaginária sobre o modelo da conformação do estado nacional francês. Por esse modelo, difunde-se a ideia de uma língua para uma nação e um Estado, não havendo espaço para a convivência entre diferentes línguas, visto que apenas uma língua passa a ser significada como aquela que representa determinado Estado-Nação. No caso de um país em situação de bilinguismo, uma questão coloca-se no âmago da constituição do próprio Estado. A unidade linguística imaginária que garantiria a unidade do Estado tem que ser "furada". É preciso ultrapassar a barreira do uno para que possa haver a produção de um Estado nacional efetivamente bilíngue. A questão que nos colocamos neste ponto é simples: o Paraguai é uma nação bilíngue? Ou ainda, como é possível uma nação bilíngue?

Neste momento, não queremos responder a esse questionamento - que soa como provocação na análise de um país bilíngue -, mas direcionar nosso olhar para os três projetos levados a cabo no ano de 2014 pela Secretaria de Políticas Linguísticas do Paraguai, a saber: 1. Projeto: Rohayhu Che Ñe'ẽ : una semana en lengua guaraní; 2. Projeto: Normalización del uso de la lengua guaraní en las instituciones públicas; 3 . Projeto: Normalización del uso de la lengua guarani en los departamentos ${ }^{5}$.

Os projetos antes mencionados foram publicados pela Secretaria de Políticas Linguísticas e, até o momento, apenas o primeiro, "Rohayhu Che Ñe'ẽ: una semana en lengua guaraní", foi concretizado e finalizado, no mês de agosto de 2014. Os projetos seguintes foram iniciados, por meio de convênios feitos para sua realização, que se encontra em andamento $^{6}$. Por esse motivo, procederemos a uma análise apenas do primeiro projeto intitulado Rohayhu Che Ñe'ẽ.

\section{Rohayhu Che Ñe'ẽ.}

Neste ponto, passamos a nos concentrar no primeiro projeto, que previa uma semana de uso da língua guarani, o Rohayhu Che Ne', e que foi implementado em agosto do ano de 2014. Consideramos tal projeto como um gesto de política de línguas explícita no espaço de enunciação paraguaio na atualidade. 
Proyecto Rohayhu Che Ñe' ẽ : Una semana en lengua guaraní, impulsado a fin de promover la revalorización y el normal uso oral y escrito del idioma guaraní, a través de una experiencia de inmersión lingüística, por una semana, invitando al Estado, los medios de comunicación y la sociedad a vivir en y con esta lengua durante unos días; éstas actividades colaborarían a elevar el estatus de esta lengua y el orgullo de la población hacia ella, y así seguir el proceso de normalización de su uso. Durante seis días, del lunes 25 al sábado 30 de agosto, se invitó a toda la población y a los compatriotas radicados en el exterior a vivir en la lengua guaraní, es decir, que usen solo o preferentemente esta lengua, en forma oral y escrita, en todas las interacciones comunicativas, especialmente en los espacios no habituales de su uso ${ }^{7}$.

O trecho acima reproduzido é a descrição do Rohayhu Che $\tilde{N} e^{\prime} \tilde{e}$ : Una semana en lengua guaraní. A partir da leitura desse projeto, podemos afirmar que, no caso paraguaio, a contradição está posta e dissimulada, ou, em termos discursivos, a ideologia faz parecer evidente o lugar das línguas que ali disputam o espaço. O projeto formulado e promovido pela Secretaria de Políticas Linguísticas do Paraguai estabelece como objetivo o uso da língua guarani em todos os âmbitos da comunidade paraguaia, principalmente, aqueles em que não se utiliza o guarani, ou seja, os ambientes vinculados às instituições públicas, aos meios de comunicação etc. A proposta em si já revela que o guarani ainda ocupa o lugar da oralidade naquele país e que, nas situações formais de uso linguístico, o espanhol ainda é a língua oficial. Pressupõe-se, ao chegar a qualquer instituição pública, principalmente na capital do país, o uso da língua de origem europeia.

Em 2005, Corvalán sinalizava para esse uso da língua guarani fora dos espaços institucionais do Estado. Segundo a autora,

Os símbolos de vitalidade da língua dão a possibilidade de medir o alcance e impacto das mudanças no uso, no setor público, privado e em áreas de grande visibilidade como: Governo, administração pública, sinalização de espaços públicos, comércio, propaganda, mercado de trabalho etc. Entretanto, foi inexistente o avanço em áreas de prestígio como a jurídica, legislativa e principalmente nas instituições do Estado; nos símbolos (moedas e notas, selos e carimbos, passaportes, carteiras de identidade etc.), nos folhetos oficiais do Governo, ainda que haja ocorrido um avanço nas notas novas com o valor do Guarani impresso em ambas as línguas. (CORVALÁN, 2005.) 
Tal como afirmava Corvalán (2005) com relação à época anterior à implementação da Lei de Línguas, em que era "inexistente o avanço" da língua guarani "em áreas de prestígio", podemos afirmar que, atualmente, a situação das línguas no Paraguai não teve grande mudança. É possível dizer que cinco séculos não mudam em vinte anos. Apesar da resistência produzida pelos projetos políticos, esse resistir significa, dentro do sistema já conformado de um imaginário de bilinguismo, que não promove uma situação de paridade entre as duas línguas.

A falha no processo de implementação da Lei de Línguas denuncia o funcionamento do lugar das línguas no imaginário paraguaio que, passados já mais de vinte anos da oficialização do guarani, reserva-lhe o lugar da oralidade, o lugar da língua materna, língua "patrimônio" - nesse último caso, pelos dizeres de uma nação constituída a partir de um processo de colonização.

Rohayhu Che Ñe' ẽ aparece como o "furo" na evidência quando se diz das línguas oficiais do Paraguai. O projeto promovido no mês de agosto de 2014 faz lembrar o que se esquece (PÊCHEUX, 1988 [1975]), na construção das evidências, ao dizer sobre o guarani e o espanhol em situação de bilinguismo. Se se considera que o Paraguai é bilíngue e não se reconhece a contradição, apaga-se a possibilidade de mudança e cada vez mais o projeto de bilinguismo faz silenciar os possíveis sentidos para a língua guarani naquele país. Se "todo mundo sabe" (PÊCHEUX, 1988 [1975]) que no Paraguai se falam guarani e espanhol, que todo paraguaio é bilíngue, onde se encaixam os que não falam espanhol? Como se muda algo que já está pronto como é o caso do bilinguismo?

Este movimento que faz reconhecer o bilinguismo e produz sentidos que alimentam o imaginário que projeta as línguas no Paraguai como oficiais e, portanto, "equivalentes" vai deixando escapar e apagando, no mesmo gesto, a língua guarani, as línguas indígenas - o guarani indígena, o mbya guarani e outras línguas -, a língua da fronteira e a língua das colônias. Nesse funcionamento, sob a ilusão do bilinguismo, encobre-se o real e silenciam-se sentidos aí presentes.

Mostra-se, na contradição de um programa lançado pela Secretaria de Políticas linguísticas do Paraguai, a falha no processo de oficialização de uma língua indígena e do projeto bilíngue, conservando-se assim o funcionamento ideológico construído historicamente, que permitiu ao espanhol ocupar o lugar da unidade real oficial, revelando a contradição que marca a relação entre as línguas nesse espaço. 
Diz-se que o Paraguai é um país bilíngue, mas, ainda de acordo com o censo de 2002 , mais de $80 \%$ da população declarou seus lares "falantes de guarani”, principalmente nas zonas rurais: famílias inteiras, cujos direitos são restritos ao uso do espanhol, uma língua que muitos desconhecem, pela qual seguem sendo colonizados ano após ano. Os monolíngues em guarani são silenciados no seu próprio país. E eles não são poucos.

\section{Concluindo: a promoção do bilinguismo ima- ginário}

Ao longo de nossa pesquisa, fomos construindo um arquivo de análise que nos permitiu compreender o imaginário sobre o bilinguismo paraguaio na ordem do simbólico. Na tensão entre promover um guarani do impossível, sem sentido para o falante do dia a dia, e o guarani paraguaio, resultado do confronto histórico da colonização linguística (MARIANI, 2004), no espaço de enunciação paraguaio, as políticas de línguas pró-bilinguismo significam-se por um "vir a ser" em que há um futuro possível para o guarani, mas (ainda?) não realizável.

No campo da sociolinguística, a discussão sobre o termo bilinguismo teve uma grande produção nos anos sessenta e tem em Fishman (1967) um nome fundamental. Em sua produção, Fishman (1967) diferencia bilinguismo e diglossia para afirmar que o bilinguismo supõe uma igualdade nas relações e que, na diglossia, haveria uma divisão funcional que afetaria os usos das línguas nessa situação ${ }^{8}$.

Do ponto de vista discursivo, perguntamo-nos: é possível bilinguismo sem diglossia?? Seria o Paraguai um exemplo de bilinguismo ou de diglossia? O que estamos querendo formular é que, de nosso campo teórico, seria da ordem do impossível considerar a convivência de duas línguas de forma harmônica, produzidas a partir da dominação histórica, ideológica e linguística pelas quais passaram os países colonizados. A partir dessas considerações, ainda nos perguntamos: as políticas de línguas do Estado paraguaio, ao promoverem projetos para o bilinguismo, de fato promovem uma situação de equivalência entre os usos das duas línguas oficias?

A memória da colonização inscreve-se nos discursos sobre as línguas e, como resultado desse processo de discursivização do bilinguismo, a suposta equivalência entre as línguas guarani e espanhola, no espaço paraguaio, produz um silenciamento da língua significada como patrimônio da nação e símbolo da identidade cultural em oposição àquela significada como língua da civilização e da cidadania. 
A ideologia do valor de uma língua, pela globalização ou pelo mito da comunicação mundial, silencia a tensão histórica de dominação que produz efeitos de sentido sobre as línguas envolvidas nesse projeto. Trata-se de uma discursividade que produz um apagamento do repetível na história dos países colonizados, ou seja, um apagamento que atua em favor da promoção de um monolinguismo em língua espanhola no Paraguai.

Pela formulação de um enunciado que se repete na ordem do simbólico - "El Paraguay es un país pluricultural y bilingüe", como se lê na Constituição da República do Paraguai, 1992 -, ficam silenciadas as disputas que produzem, de modo contínuo, um país cada vez mais monolíngue em língua espanhola ${ }^{10}$.

A esse respeito, verificamos como discursivamente se produziu - e se produz - um bilinguismo imaginário pelo próprio Estado paraguaio, a partir das suas políticas de línguas. De nossa perspectiva, a noção de bilinguismo imaginário justifica-se pela relação com a língua nacional, que é também da ordem do imaginário, que, pela representação da situação linguística do Paraguai, atualiza a memória da colonização nos documentos produzidos pelo governo. Ou seja, consideramos o bilinguismo imaginário como parte de um processo histórico de colonização linguística (MARIANI, 2004) em que se apagam as relações de forças nas discursividades que silenciam o guarani, fazendo significar as línguas espanhola e guarani em sua suposta e impossível equivalência. Nesse processo, a língua significada como mais adequada e completa, o espanhol, garante seu lugar privilegiado historicamente nas práticas políticas do Estado pelo bilinguismo. Ressaltamos que o bilinguismo imaginário é um projeto do Estado e que não estamos tratando da sociedade paraguaia e de suas manifestações linguísticas, por este se tratar de um país multilíngue, o que não se privilegia na Constituição de 1992 e nas políticas de línguas do Estado. Este seria outro estudo, que não se vincularia a uma noção de bilinguismo imaginário, talvez fosse possível pensar em um multilinguismo fluido, o que seria outro tema. Por fim, pelo que se promove como bilinguismo, podemos afirmar que o bilinguismo imaginário institui um lugar para as línguas nacionais, produzindo efeitos de sentido para os paraguaios, subjetivados nesse processo, significando-os pela imagem de um sujeito nacional bilíngue.

Partindo do deslocamento proposto do conceito de bilinguismo para a noção de bilinguismo imaginário, perguntamo-nos: qual a imagem do sujeito nacional paraguaio (bilíngue) promovido pelas/nas políticas 
de línguas do Paraguai? Na relação com o Estado, pela implementação de uma língua oficial, conseguimos observar duas direções de sentido produzidas pelas políticas de línguas do estado paraguaio. 1. o falante de guarani, para ter seus direitos reconhecidos, defendidos e, inclusive, para compreendê-los e ser compreendido, deve aprender a língua espanhola; 2. o falante de espanhol, no mesmo contexto, já tem o conhecimento linguístico necessário para reivindicar seus direitos, ele não precisa aprender o guarani.

Se nos perguntamos: "em que língua é possível ser cidadão no Paraguai?" e "em que língua o sujeito se submete ao jugo do Estado?", podemos afirmar que o ser cidadão no Paraguai está determinado pelo funcionamento de um Estado com características monolíngues, cuja realidade plurilíngue é admitida, mas não praticada.

Nas ruas do país, o Paraguai se manteve praticamente monolíngue em guarani, principalmente nas zonas mais afastadas dos centros urbanos. Nos meios de comunicação, nas placas de trânsito e em todo o aparato produzido, incluindo seus aparelhos ideológicos (ALTHUSSER, 2003 [1971]), o Estado se conforma como monolíngue em espanhol.

O lugar atual das línguas nas políticas de línguas no Paraguai faz significar a memória da colonização, atualizando-a, fazendo ressoar os sentidos para a língua guarani como símbolo de um patrimônio nacional. Na relação estabelecida entre o real e as leis que tratam da questão das línguas no Paraguai, podemos afirmar que há uma distância significativa a ser percorrida.

\section{THE LANGUAGE POLICIES ABOUT THE GUARANI IN PARAGUAY AND THE IMAGINARY BILINGUALISM}

This paper is based on our doctoral thesis in which we discursively analyze the role the Guarani language plays as an official language in Paraguay nowadays. The theoretical framework adopted is the field of the History of Linguistic Ideas (AUROUX, 1998, 2009 [1992], 2010 [1994]; ORLANDI, 1983, 1988, 2008 [1990]), in its interlacement with the Discourse Analysis of the French line (PÊCHEUX, 1988 [1975], 1990 [1969]; 2010 [1994]). With the objective of comprehending the meanings produced around the 
imaginary of bilingualism, we analyzed the actions of the Secretariat of Linguistic Policies, from the description of three projects, among which we selected the one entitled Rohayhu Che Ñe'ẽ: una semana en lengua guaraní. We observed the functioning of the discourses about the Guarani in the Paraguayan and also in the Latin-American space of enunciation (GUIMARÃES, 2005), for its incorporation as an official working language in Mercosur. By the analysis undertaken, it was possible to verify how the memory (PECHEUX, 2007) about the languages is inserted in the production of language policies about the bilingualism, by the promotion of an imaginary bilingualism. In the battle between the languages, in the textualities analyzed, the effects of meaning ideologically and historically produced are materialized, in a process that continues to promote the Spanish language and to mute the Guarani language in Paraguay.

KEYWORDS: History of linguistic ideas; language policies; guarani language; imaginary bilingualism.

\section{NOTAS}

1 “Rohayhu Che Ñe'ẽ: uma semana em língua guarani”. (Tradução nossa.)

${ }^{2}$ Comunidade dos Países de Língua Portuguesa.

${ }^{3}$ Referimo-nos, aqui, a um trecho da carta de Pero Vaz de Caminha: "Eram pardos, todos nus, sem coisa alguma que lhes cobrisse suas vergonhas. Nas mãos traziam arcos com suas setas. Vinham todos rijos sobre o batel; e Nicolau Coelho lhes fez sinal que pousassem os arcos. E eles os pousaram. Ali não pôde deles haver fala, nem entendimento de proveito, por o mar quebrar na costa." (CAMINHA, p. 03) Disponível em: http://objdigital.bn.br/Acervo_Digital/Livros_eletronicos/carta. pdf. Acesso em: 10 de dezembro de 2014.

${ }^{4}$ Nossas perguntas são baseadas nas formulações de Jiménez (2011), Zarratea (2011), Melià (2013) sobre as discussões que tratam do purismo da língua guarani. 5 “Projeto: Rohayhu Che Ñe' é : uma semana em língua guarani; 2. Projeto: Normalização do uso da língua guarani nas instituições públicas; 3. Projeto: Normalização do uso da língua guarani nos estados." (Tradução nossa.) 
${ }^{6}$ Fonte: Secretaria de Políticas Linguísticas do Paraguai. Disponível em: www. spl.gov.py. Acesso em: 10 de outubro de 2014.

7 “Projeto Rohayhu Che Ñe' ẽ : Uma semana em língua guarani, impulsionado a fim de promover a revalorização e o normal uso oral e escrito do idioma guarani, a partir de uma experiência de imersão linguística, por uma semana, convidando o Estado, os meios de comunicação e a sociedade a viver em e com esta língua durante uns dias estas atividades colaborariam para elevar o status desta língua e o orgulho da população por ela, e assim seguir o processo de normalização do seu uso. Durante seis dias, da segunda 25 ao sábado 30 de agosto, foi convidada toda a população e também os compatriotas radicados no exterior a viver em língua guarani, ou seja, que usassem só ou preferentemente essa língua, de forma oral e escrita, em todas as interações comunicativas, especialmente nos espaços não habituais de seu uso." (Tradução nossa)

${ }^{8}$ Vale ressaltar que, até este momento, trabalhamos com a noção de "bilinguismo" tal como aparece descrita na Constituição de 1992. Trouxemos o termo "diglossia" da sociolinguística para discutir como, para nós, discursivamente, ambos os termos não dariam conta de nosso objeto, as políticas de promoção da língua guarani pelo estado paraguaio.

${ }^{9}$ Vale a pena lembrar o texto, proferido por Melià (1988), em que o autor dirá que não há bilinguismo no Paraguai e sim diglossia. Mais recentemente, em La tercera lengua del Paraguay, Melià (2013) afirma que, no Paraguai atual, não se trata nem de bilinguismo nem de diglossia, o que há é uma terceira língua. (MELIÀ, 2013)

${ }^{10}$ Dados do Censo do Paraguai do ano de 2002.

\section{REFERÊNCIAS}

ALTHUSSER, Louis. Aparelhos ideológicos do Estado. 9 ed. Rio de Janeiro: Editora Graal, 2003 [1971]. (Biblioteca de Ciências Sociais).

AUROUX, Sylvain. A revolução tecnológica da gramatização. $2^{\mathrm{a}} \mathrm{ed}$. Campinas, SP: Editora da Unicamp, 2009 [1992]). 144p.

. A hiperlíngua e a externalidade da referência. In: ORLANDI, Eni P. (Org.) [et al]. Gestos de leitura. Da história no discurso. Trad. de Bethania Mariani [et al]. $3^{\text {a }}$ ed. Campinas, SP: Editora da UNICAMP, 2010 [1994]. p. 241-251.

. Língua e hiperlíngua. In: Línguas e instrumentos linguísticos. Número 01. Campinas, SP: Pontes Editores e Projeto História das Idéias Linguísticas no Brasil, 1998. p. 17-31. 
BRANCO, Luíza Kátia Castelo. A língua em além-mar: sentidos à deriva - o discurso da CPLP sobre língua portuguesa. Tese de Doutorado. Campinas, SP: [s.n], Unicamp, 2013. 325p.

CELADA, María Teresa. O espanhol para o brasileiro: uma língua singularmente estrangeira. Tese de doutorado. Campinas, SP: [s.n] Unicamp, 2002. 277p. CORVALÁN, Graciela. La vitalidad de la lengua guaraní en el tercer milenio. 2005. Disponível em: http://www.datamex.com.py/guarani/opambae_rei/

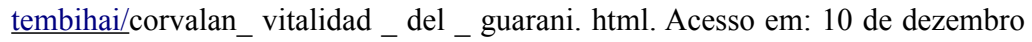
de 2014.

FISHMAN, Joshua. Bilingualism with and without Diglossia, Diglossia with and without Bilingualism. Journal of Social Issues, 1967.

GADET, Françoise. PÊCHEUX, Michel. A língua inatingível: o discurso na história da linguística. $2^{\mathrm{a}}$ ed. Campinas, Editora RG, 2010 [1981].

GUIMARÃES, Eduardo. Semântica do acontecimento: um estudo enunciativo da designação. $2^{\text {a }}$ ed. Campinas, SP: Pontes Editores, 2005. 96 p.

HAROCHE, Claudine. Fazer dizer. Querer dizer. Trad. Eni P. Orlandi. São Paulo: Editora Hucitec, 1992. 224 p.

MARIANI, Bethania. PCB e a imprensa. Os comunistas no imaginário dos jornais (1922-1989). Campinas, SP: Editora da UNICAMP, 1998.

Colonização linguística: línguas, política e religião no Brasil (séculos XVI a XVIII) e nos Estados Unidos da América (século XVIII). Campinas: Pontes, 2004.

. Da Colonização Lingüística Portuguesa à Economia Neoliberal: nações plurilíngües. In Gragoatá, 2008.

Quanto vale uma língua? O apagamento do político nas relações econômicas e linguísticas. In: Revista Encontros de Vista. 2a ed, 2008 b.

MELIÀ, Bartomeu. Diglosia en el Paraguay - o la comunicación desequilibrada. In: ORLANDI, Eni. (Org.) Política linguística na América Latina. Campinas, SP: Pontes Editores, 1988.

. La tercera lengua del Paraguay y otros ensayos. Colección Academia Paraguaya de la Lengua Española. Asunción, Paraguay, 2013. 207 p.

NIRO, Mateo. El guaraní como lengua oficial: entre el nacionalismo y la integración regional. In: CELADA, María Teresa. FANJUL, Adrián Pablo. NOTHSTEIN, Susana. Lenguas en un espacio de integración: acontecimientos, acciones, representaciones. Buenos Aires: Editorial Biblos, 2010. p. 209-235.

ORLANDI, Eni. SOUZA, Tânia C. C. Língua fluida e língua imaginária. OR- 
LANDI, Eni. (Org.) Política linguística na América Latina. Campinas, SP: Pontes Editores, 1988.

ORLANDI, Eni P. A linguagem e seu funcionamento: as formas do discurso. São Paulo: Editora Brasiliense, 1983. 238 p.

. Terra à vista. Discurso do confronto: velho e novo mundo. 2 ed. Campinas, SP: Editora da Unicamp, 2008 [1990]). 288 p.

PÊCHEUX, Michel. Análise Automática do Discurso. Trad. Eni P. Orlandi. In: GADET, Françoise. HAK, Tony. (Org.). Por uma Análise Automática do Discurso. Uma Introdução à Obra de Michel Pêcheux. Campinas, SP: Editora da Unicamp, 1990 [1969]), p. 61-161.

. Semântica e discurso: uma crítica à afirmação do óbvio. Trad. Eni P. Orlandi et al. Campinas, SP: Editora da Unicamp, 1988 [1975]. 317 p.

. Ler o arquivo hoje. Trad. Maria das Graças Lopes Morin do Amaral. In: ORLANDI, Eni. [et al.] Gestos de leitura: da história no discurso. $3^{\mathrm{a}}$ ed. Campinas, SP: 2010 [1994], p. 49-59.

. Papel da Memória. In: ACHARD, Pierre. (Org.). Papel da Memória. 2 ed. Campinas, SP: Pontes, 2007, p. 49-57.

SERRANI, Silvana Mabel. A paráfrase como ressonância interdiscursiva na construção do imaginário de língua - o caso do espanhol riopratense. Tese de Doutorado. Campinas, SP: [s/n] Unicamp, 1991. 327 p.

ZARRATEA, Tadeo. La Ley de Línguas del Paraguay. Comentada, concordada, traducida al guaraní y sus antecedentes. Asunción: Servilibros. R. L., 2011.

Recebido em: 01 de fevereiro de 2016

Aceito em: 25 de abril de 2016 